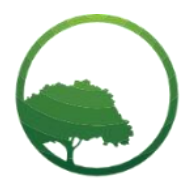

Research in Business \& Social Science

IJRBS VOL 11 NO 1 (2022) ISSN: 2147-4478

\title{
Consumer purchase behaviour of perishable products from selected stores in Durban
}

\author{
(D) Paballo Patience Ntobaki (a) (iD) Raymond Hawkins-Mofokeng (b) (D) Tshepo Tlapana ${ }^{(c)}$ \\ ${ }^{(a)}$ Ph.D Student, Department of Marketing \& Retail, Durban University of Technology, Durban, South Africa \\ ${ }^{(b)}$ Lecturer, Department of Marketing \& Retail, Durban University of Technology, Durban, South Africa \\ ${ }^{(c)}$ Senior Lecturer, Department of Corporate Communications \& Marketing, Walter Sisulu University, East London, South Africa
}

\author{
ARTICLE INFO \\ Article history: \\ Received 23 December 2021 \\ Received in rev. form 04 Feb. 2022 \\ Accepted 06 February 2022 \\ Keywords: \\ Category Management; Perishable \\ Products; Consumer Behaviour \\ JEL Classification: \\ M3, M30, M31, L81
}

\begin{abstract}
A B S T R A C T
The determination of retailers to deal with the challenges of managing perishable products' category continues as they persist to provide quality service and fresh products to their customers. These challenges often afflict retailers and consumers alike, which innately impact category management and good consumer behaviour. This article reports on a study that investigates the influence of category management on consumer's purchase behaviour of perishable products. The objectives of this article are to determine the influence of category management on purchase behaviour, to explore the current retail category management practices for perishable products, and to investigate the relationship between pricing and shelf life of perishable products and how this relationship influences consumers' purchase behaviour. To achieve these objectives, in-depth semi-structured qualitative interviews that were explorative by nature were conducted, with ten (10) staff members of a selected store in Durban, South Africa, who were responsible for the perishable products category. The findings reveal that category management does influence the purchase behaviour of perishable products; however, problems were identified concerning assortment planning, shelving, promotions, pricing, and shelf life. The results were limited to this Durban store. Recommendations were made to the retailers to solve those problems to effectively satisfy consumers.
\end{abstract}

() 2022 by the authors. Licensee SSBFNET, Istanbul, Turkey. This article is an open access article distributed under the terms and conditions of the Creative Commons Attribution (CC BY) license (http://creativecommons.org/licenses/by/4.0/).

\section{Introduction}

The South African retail sector is a major contributor to the commercial advancement in the country, whereby consumers are demanding authenticity and transparency to allow them to make careful consumption choices of perishable merchandise (Thompson, 2018). According to Hawkins-Mofokeng, Maurizio, and Hingley (2017) nowadays consumers are more anxious about product safety and traceability in the supply chain as far as quality standards are concerned. When it comes to deciding which products to include in an assortment for a certain category and how to store, price, and promote them would rely on a distinct retail strategy that states which shoppers are preferential to the retailer linked with a conception of the effect that merchandise in one category has on one another (Nielsen, 2006:68). Hence, new developments have focused on product categories instead of just specific products or brands to determine the performance of the retail industry (Ramaseshan, Achutan, and Collison, 2009:458). However, it remains difficult with fresh produce where there is a lot of inefficiencies such as wastage, repacking, out of stocks, and discounted sales which are hidden expenses that cannot be easily controlled, in this case, the retailer has to work closely with suppliers to develop strategies to market excess supply (O’Keeffe, 2013).

\footnotetext{
* Corresponding author. ORCID ID: 0000-0002-1777-6177

(C) 2022 by the authors. Hosting by SSBFNET. Peer review under responsibility of Center for Strategic Studies in Business and Finance.

https://doi.org/10.20525/ijrbs.v11i1.1559
} 
It is very important to take cognisance that South Africa was previously in a financial downturn before the coronavirus (COVID-19) pandemic due to fundamentally feeble government money, continuing electricity shortages, dreary business development, and lessening business and consumer confidence. As a result of the lockdown imposed, the consumer goods industry in South Africa is facing severe disruption (Euromonitor, 2021). Moreover, the economic concerns will have an average to enduring influence on fastmoving consumer goods (FMCGs) due to regulations presented as part of the lockdown, fluctuations in consumer behaviour, and supply chain disturbance, and in turn affecting consumers in terms of their buying patterns. According to Butu, Brumă, Tanasă, Rodino, Vasiliu, Dobos, and Butu, (2020) this epidemic prompted huge deviations in economics, local and worldwide rules, social behavior, and natives' attitudes beyond everything else. Regardless of the current tussles posed by this challenge, industries are still striving to transform and adapt to these current changes to overcome their trials. The tangled dynamics of well-being and monetary crunches have considerably influenced consumer behaviour and posed novel encounters for firms. The business nowadays defies disturbed consumer buying patterns and augmented tendencies as well as an increase of different anxieties and some amendments of significances (Renner, Baker, Cook, and Mellinger, 2021). Nevertheless, life continues and basic needs also have to be met by these poor consumers.

In this framework, this study aims to analyse the consumer purchasing behaviour of perishable products from a selected store in Durban KwaZulu-Natal, South Africa. As a result, the following are the sections that will be covered in this study and will be dealt with in this fashion: literature review, methodology, data analysis, results, conclusion, and recommendations.

\section{Theoretical and Conceptual Background}

\section{Perishable Products}

In the context of fast-moving consumer goods retailers, merchandise assortment is often comprised of categories such as high-sales (basic) product categories that are often of low cost/profit margin like eggs, bread, and milk. As well as some impulsive categories which are usually bought without prior planning. Impulsive buying is common particularly for hedonic products like cakes (Flamand, 2017). These retailers that offer perishable products are struggling to provide the right product quantity in their stores. Normally, perishable products are delivered numerous times a week and can only be sold within a limited time due to a rapid decrease in product freshness and quality. Unsold products, on the other hand, become waste products and lead to profit loss. However, in the plight to avoid product waste retailers often run out of stock which also leads to loss as consumers are unable to purchase the products they need at a given time (Huber, Gossmann, and Stuckenschmidt, 2017). To address this challenge, retailers use category management by disintegrating this problem into a set of smaller problems which independent from one another. To accomplish this, interrelated products are grouped into a category that is autonomous from products of other categories (Musalem, Aburto and Bosch, 2018).

\section{Category management}

Category management based on the views of Varley (2006) is when groups of merchandise are strategically managed through trade partnerships to maximize sales and financial gain by meeting the needs of consumers becomes necessary. Together with strategic sourcing of products' procurement, category management is a major part of purchasing transformation that is focused on purchasing a specific product category to safeguard that sourcing, product function, and policies achieve the objectives of the corporate strategy (Landale, Apte, Rendon and Salmeron, 2017). This allows retailers to manage product categories as strategic business units (SBUs) with substantial independence. Management of each category as a strategic business unit is supported by retailers' and manufactures' partnerships which adopt the role of a category captain (Musalem et. al., 2018). Thus, category management engages all stakeholders in fully understanding merchandise requirements, cost drivers, market intelligence on market trends and risks relating to the merchandise, and developing sourcing that bring stakeholder requirements inline market realities (Landale et. al., 2017).

One of the most common trends in consumer markets is that customer demand is highly influenced by in-store factors that influence the awareness and visibility of merchandise positively during the consumer buying process. Thus, a category is not based on the product price or margins, but also consumer preferences and other options associated with customer choice influences (BianchiAguiar, Hübner, Carravillaa, and Oliveiraa, 2020). This indicates that grouping items that are assumed to have high complementarity or high similarities reduce the intricacy of retailers' problems, it overlooks opportunities that arise as a result of other types of interrelations in cross-category (Musalem et. al., 2018). Agarwal (2015) further elaborates that product that customers see as replacements of each other based on price, promotion, and are aimed at the same target market are referred to as product category assortment.

\section{Category Assortment}

Product or merchandise assortment enacts a significant part in retailing; it portrays the retailer's positioning and is a strategic determining factor of image and patronage (Hart and Rafiq, 2006). Although there is a possibility of transformation in retail product assortment to provide a wider product variety in the future to meet the individual needs of consumers is within the context of ecommerce, it has been subtly indicated otherwise for brick and mortar retailing because of high supply and demand inventory costs (Hoskins, 2020). Retailers need to constantly Identify consumer preferences and respond by providing products that meet consumer needs because of continuous changes in consumer behaviour (Saure, 2011). Niemeier, Zocchi, and Catena (2013) add that stores can also recognize which consumer needs are unmet by presenting variety, determining prospects to escalate sales by presenting new 
items as well as evaluating the degree to which the outline of a fresh item will affect sales of additional merchandise or the lost sales that will shadow the delisting of the merchandise.

Expanding category assortments to include a wide variety of products is more successful when consistently organized across product categories. This will create a strategic orientation and market image that is aligned with consumers who seek less popular and niche product offerings often found at the end of sales distribution. These types of consumers tend to extend the purchase intentions across other product categories. So, being consistent across product categories is essential for various strategic dimensions such as pricing and private-label branding. Across product types, the same approach applies to assortment variety levels (Hoskins, 2020). Given limited shelf space and budget restrictions, roper assortment planning is essential in determining a favourable merchandise mix a retailer needs to carry to maximize sales opportunities. This includes the breadth and depth of assortment, as well as the inventory level of each stock-keeping unit (Flamand et. al, 2017).

However, it is still a challenge to plan and allocate different products to scarce shelf space in a retail store. Retailers have to figure out how much shelf space to allocate to individual products and the quantity of the product to be allocated space (space assignment), the vertical level and horizontal shelf position to allocate to each product (Vertical and Horizontal allocation) (Bianchi-Aguiar, Hübner, Carravillaa, and Oliveiraa, 2020). Flamand et. al (2017) support that it is a challenge to use scarce shelf space in a way that increases customer footprint (the amount of patronage), converts visitors to buyers, and ultimately profitability. And though the breadth of product assortment and other references are the main customer attractions, converting a prospect into a buyer primarily relies on store activities with regards to store layout and space allocation.

\section{Product shelf space and Shelf life}

The objective of shelf space planning is to increase profitability by considering limited shelf space and allocation constraints when assigning products to shelves (Bianchi-Aguiar et. al., 2020). According to Hubner (2011), the corresponding customer needs with store shelf quantity is the main device to accumulate proficiency in retailing. Customers want excellent service and prices, whilst retail stores are responding by a broad merchandise assortment and getting to be more competitive in price and service level. Location of the item within the display, its displayed facing area, and visual features of its display like size and colour coordination with regards to display alignments of its packaging are other shelf space management aspects besides price that influence the demand of a product (Murray, Tulukar and Gosavi, 2010).

Due to the scarcity of shelf space, particularly in smaller retail stores located in densely populated urban areas, some product categories may not be feasible to include as retailers have to optimize shelf space allocation when determining retail merchandise mix including low-profit fast-movers and high-profit impulse product categories. Assigning fast-movers to convenient areas of the store can result in a positive shopping experience for planned purchases and improve customer loyalty while placing (some of them) very noticeable shelf areas for high impulse product categories can inspire unintended purchases and generate additional revenue (Flamand, 2017).

However, one of the problems faced by retailers of perishable products is having a fixed number of items to sell, as well as inadequate time in which to sell them before the products lose their value (Sweeting, 2010:2). Perishable products are characterized by highly indeterminate demand and obsolescence. Traditional product management is typically not appropriate for perishable products because the perishable products may expire during the transportation process of storage and would then be disposed of with handling cost. Managing perishable products such as meats and packed fresh foods with only a few days' shelf-life is specifically challenging. As soon as the shelf-life of a product decreases, its usefulness is over. As a result, there is a high wastage risk when products are stocked in excess too often to reduce the risk of product shortage. On the other hand, product shortage often due to limited inventory can result in a loss of reputation, loyalty, and financial status (Chen, Xiao, Wang and Lei, 2020).

\section{Price Promotions}

To the retailer, the economic appeal of price promotions is more complex to measure. The retailer's performance is not only associated with all brands in the category instead of sales of any one brand but it is also based on category interdependencies and the store-traffic effects of promotions (Srinivasan, Pauwels and Hassens, 2014). Levy and Weitz (2010) added that sales promotions, which are a commonly used type of promotions, provide benefits and enticements to consumers to patronize the store or to make purchases during certain periods. Promotions are pertinent communications tools for which under certain conditions consumers regard them as interpersonal efforts and benefits offered by the brand. Although some promotions may come in the form of price reductions or price-based value creation, they are a great tool for developing consumer brand perceptions (Mussol, Aurier, and Sere de Lanauze, 2018). Promotions also motivate customers to purchase immediately in a large quantity and consume it faster triggering growth in sales and eventually profitability (Pauwels, Hanssens and Siddarth, 2002).

However, discounting policies can have significant strategic consequences for retailers particularly in the perishable products category which includes products such as milk and bread, and where promotions are predominant (Chua, Mokhlesi and Sainathan, 2017). There is a substantiation that short and long-run efficiency of price reductions is greater for perishable products than other categories and often reducing the price of perishable products close to their expiration may date look like an operative to avoid losing profits due to spoilage (Tsiros and Heilman, 2005). Chung and Li (2013) highlight that consumers think the pricing is prejudiced as they are more aware of expiry dates under current pricing strategies. On the other hand, strategic customers always wait for a 
reasonable price to make a purchase during the price reduction period and gain full effectiveness of consumption therefore, shoppers' behaviour is one of the main factors that influence pricing mechanism as some shoppers are more price-sensitive done others during the consumer buying process (Zhou and $\mathrm{Li}, 2014$ ).

Despite the prevailing challenges posed by the COVID-19 pandemic and their impact on the fast-moving consumer goods industry, literature shows and maintains that there are some existing gaps when it comes to the fluctuating consumer purchasing behaviours and spending patterns on perishable products, which are caused mainly by price sensitivity and other related factors/dynamics.

\section{A Qualitative and Explorative Research}

This study was qualitative and explorative in nature. Interviews were conducted with ten (10) staff members responsible for a perishable products category of a selected store in Durban. Non-probability sampling was used. Participants were selected using purposive sampling to enable the researcher to select the most productive sample. To yield dependable and comparable data, an indepth semi-structured interview was chosen to collect data for this study. Based on the title, objectives, and the problem statement of the study, open-ended probing questions, which lasted for approximately forty-five (45) minutes, were designed to collect data for this study. These were informed by the literature review.

Data analysis from sources such as interviews, observations, and documentation is referred to as qualitative data analysis, and it entails responsibly presenting what the data shows (Caudle, 2004). Therefore, this process requires creativity, discipline, and a systematic approach. The core of qualitative analysis lies in the processes of describing phenomena, classifying them, and seeing how the concepts interconnect (Dey, 2003).

As a result, qualitative analysis software was used to register, code, and evaluate responses (NVivo). The program is a powerful qualitative data analysis tool with features that go way beyond what one would find in a typical statistics kit. This program was designed to help researchers conduct qualitative research by providing simple tools for data organization and analysis (Castleberry, 2014:1). The program assisted in the management, shaping, and analysis of unstructured data, reducing a large number of manual tasks and giving the researcher more time to uncover patterns, identify themes, and draw conclusions (Hilal and Alabri, 2013).

The researchers then undertook the events of formulating and analyzing data personally as the obligation was neither challenging nor strenuous. This was also to guarantee the precision and consistency of the ultimate outcomes. The analysis was done by transcribing data collected with the use of an audiotape (voice recorder) and deducing data legibly and plausibly by recording it on a hard copy. The data was then interpreted utilizing axial and selective coding of grounded theory, followed by a summary linking both the interviews and digging out the main information of category management for perishable products of their store.

\section{Credibility and Trustworthiness}

Credibility is an intuitive term that refers to a person's assessment of a piece of information's accuracy, and ensuring credibility is one of the most important factors in establishing trustworthiness. In conducting qualitative research, Guba and Lincoln substituted reliability and validity with the parallel concept of trustworthiness containing four aspects: credibility, transferability, dependability, and conformability (Mandich, Polatajko and Rodger, 2003).

As a result, the researcher cross-checked individual opinions and perceptions with those of staff members responsible for a perishable products category to ensure authenticity and trustworthiness. The researcher gave enough time to the staff members while collecting data to gain a thorough understanding and create a trusting relationship, as well as to develop long-term engagement, which entailed building confidence and rapport with respondents to foster rich, comprehensive responses. (Cope, 2014). Different methods like observations, audit trails, member checks when coding, categorizing, or confirming results with participants were employed. The researcher revisited data repeatedly to see whether the constructs, categories, explanations, and interpretations made sense and that they were error-free.

\section{Implications}

\section{Category management}

"Similar products are better managed as a group despite the competitiveness". A mutual response of the participants was their clear understanding of the topic and their confidence that it is a good practice to manage perishable products as a group as customers easily find the products in the store and the customers' ability to switch to other products in the same category should they not find their favourite products. However, participants' accounts revealed that the retailer has merchandise that is not selling well because of competition with other products in the same category. It was also revealed that product competition can be very severe when competing with items that are substitutes for one another.

\section{Assortment planning}

"A category must have a wide variety of products that caters for all demographics within the target market". This response demonstrated a strong belief that a category has to have a wide range of products in different brands to cater to the different needs of customers from different religious groups and income levels. 
Participants stated that retailer has a wide variety of products in the same category, which creates confusion among customers as they have too much to choose from.

\section{Shelving}

"Presentation of merchandise is essential". Both participants believe that customers have to be attracted to the products by the display. However, one respondent highlighted that a full shelf attracts customers, therefore when they have few items left on the shelves, they fill the shelves with different merchandise to create a perception that they have enough stock which at times creates confusion among customers and the possibility of losing customers' trust.

\section{Pricing and shelf life}

"Prices are set high but get reduced in line with the product shelf life". Respondents indicated that they price fresh products high to cover the costs of markdowns as perishable products have a short shelf life. They also purchase more enough merchandise because of suppliers' purchase deals with the hope that merchandise will sell fast. This leads to a lot of markdowns and shrinkage.

\section{Promotions}

"Promotions encourage consumer purchases". Both respondents pointed out that they get higher sales in the perishable category during promotions. It was also highlighted that fixed promotion days are avoided as customers strategically wait for such days and purchase in large quantities to shun high prices.

\section{Conclusion}

Theoretical evidence in the literature review and results from the findings reflected that the shelf life of a product has a strong influence on pricing practices as perishables products have a short shelf life. As literature in this study has provided an understanding of indispensable variables of category management, the results from the findings have validated that category management influence consumers' purchase of perishable products by establishing that customers are not only influenced to purchase perishable products because of price but, quality, value, assortment, and presentation as well. This study concludes that a well-positioned category, with enough and well-priced merchandise, will attract customers of its kind, and produce satisfactory profits. It is also concluded that category management is extensive and dynamic. Therefore, consumers' ever-changing purchase behaviour should be constantly evaluated to establish tactics that are aligned with consumers' dynamic needs.

It is recommended that retailers should practice demand-driven replenishment to avoid wastage and severe markdowns. The perishable products category has products with the shortest life of all categories in the store. Thus, retailers need to limit the amount of inventory to trends of product demand to avoid losing profits to markdowns.

Acknowledgement We would like to express our appreciation to all of the research participants and retailers.

Author Contributions: Conceptualization, P.N., R.H. and T.T.; methodology, P.N., R.H. and T.T.; validation, P.N., R.H. and T.T.; formal analysis, P.N., R.H. and T.T.; investigation, P.N., R.H. and T.T.; resources, P.N., R.H. and T.T.; writing-original draft preparation, P.N., R.H. and T.T.; writing—review and editing, Z P.N., R.H. and T.T.; supervision, T.T.; project administration, P.N.; funding acquisition, R.H.

Funding: There Was no specific funding

Informed Consent Statement: "Informed consent was obtained from all subjects involved in the study.

Data Availability Statement: The data presented in this study are available on request from the corresponding author. The data are not publicly available due to restrictions.

Conflicts of Interest: The authors declare no conflict of interest.

\section{References}

Argwal, 1. (2015). Category Management: Definitions, Significance and 8 Steps Process. Available: www.yourarticlelibrary.com. (Accessed 29 September 2015).

Butu, A. Brumă, L, S. Tanasă, L. Rodino, S. Vasiliu, C, D. Dobos, S., \& Butu, M. (2020). The Impact of COVID-19 Crisis upon the Consumer Buying Behavior of Fresh Vegetables Directly from Local Producers. Case Study: The Quarantined Area of Suceava County, Romania. International Journal of Environmental Research and Public Health. 17: 1-24.

Castleberry, A. (2014). NVivo 10 [Software Program]. Version 10. QSR International; 2012. American Journal of Pharmaceutical Education, 78(1), 1-2.

Caudle, S.L. (2004). Qualitative Data Analysis. In: Wholey, J.S., Hatry, H.P. \& Newcomer, K.E. eds. Handbook of Practical Program Evaluation (2 $2^{\text {nd }}$ edn). California: John Wiley \& Sons, 417-438.

Chung, J., \& Li, D. (2013). The prospective impact of a multi-period pricing strategy on consumer perceptions for perishable foods. British Food Journal, 115(3), 377-393.

Cope, D.G. (2014). Methods and Meanings: Credibility and Trustworthiness of Qualitative Research. Oncology Nursing Forum, 41(1), 89-91. 
Dey, I. (2003). Qualitative Data Analysis: A User-Friendly Guide for Social Scientists (2nd edn). London: Routledge.

Euromonitor. (2021). How Coronavirus is Impacting the FMCG Landscape in South Africa. Euromonitor International. Available: https://blog.euromonitor.com/how-coronavirus-is-impacting-the-fmcg-landscape-in-south-africa/. (Accessed 07 April 2021).

Hart, C., \& Rafiq, M. (2006). The dimensions of assortment: A proposed hierarchy of assortment decision making. Int. Rev. of Retail, Distribution and Consumer Research, 16(3), 333-351.

Hawkins-Mofokeng, R., Canavari, M., \& Hingley, M. (2017). The marketing implications of value chain governance strategies of wine products using geographical indications (GIs) in Italy and UK. International Journal of Food and Beverage Manufacturing and Business Models (IJFBMBM), 2(2), 13-35.

Hilal, A.H., \& Alabri, S.S. (2013). Using NVIVO for Data Analysis in Qualitative Research. International Interdisciplinary Journal of Education, 2(2), 181-186.

Hubner, A. (2011). Retail Category Management: Decision Support Systems for Assortment, Shelf Space, Inventory and Price Planning. London: Springer.

Levy, M., \& Weitz, B. A. (2010). Retailing Management. $7^{\text {th }}$ ed. Boston: McGraw-Hill.

Mandich, A.D., Polatajko, H.J., \& Rodger, S. (2003). Rites of Passage: Understanding Participation of Children with \& Coordination Disorder. Human Movement Science, 22(4), 583-595.

Murray, C.C., Talukdar, D., \& Gosavi, A. (2010). Joint optimization of product price, display orientation and shelf-space allocation in retail category management. Journal of Retailing, 86(2), 125-136.

Nielsen, A. C. (2006). Consumer Centric Category Management: How to Increase Profits by Managing Categories Based On Consumer Needs. John Wiley and Sons: New Jersey.

Niermeier, S. Zocchi, A., \& Catena, M. (2013). Reshaping Retail: Why Technology is Transforming the Industry and How to Win in the New Consumer Driven World. London: Wiley \& sons.

O’Keffe, P. (2013). Fresh Food Management: Leveraging Strategic Options Available: www.agric.gove.ab.ca. (Accessed 29 September).

Pauwels, K. Hanssens, D. M., \& Siddath, S. (2002). The Long-Term Effects of Price Promotions on Category Incidence, Brand Choice, and Purchase Quantity. Journal of marketing research, 39(4), 421-439.

Ramaseshan, B. Achutan, N. R., \& Collin, R. (2009). A Retail Category Management Model Integrating Shelf Space and Inventory Levels: Asia-Pacific Journal of Operational Research, 26(4), 457-478.

Renner, B. Baker, B. Cook, J., \& Mellinger, J. (2021). The Future of Fresh: Patterns from the Pandemic. Deloitte Insight. Available: https://www2.deloitte.com/za/en/insights/industry/retail-distribution/future-of-fresh-food-sales/pandemic-consumerbehavior-grocery-shopping.html. (Accessed 06 April 2021).

Saure, D. R. (2011). Essays in Consumer Choice Driven Assortment Planning. Available: www.columbia.edu. (Accessed 29 September 2015).

Srinivasan, S., Pauwels, K., Hanssens, D.M., \& Dekimpe, M.G. (2004). Do promotions benefit manufacturers, retailers, or both? Management Science, 50(5), 617-629.

Sweeting, A. (2010). Dynamic Pricing Behavior in Perishable Goods Markets: Evidence from Secondary Markets for Major League Baseball Tickets. Available: www.econweb.umd.edu. (Accessed 29 September 2019).

Thompson, R. (2018). Opinion: Five Consumer Spending Trends to Watch out for in 2018 Available: https://www.iol.co.za/businessreport/opinion/opinion-five-consumer-spending-trends-to-watch-out-for-in-2018-13148720. (Accessed 19 March 2019).

Tsiros, M., \& Heilman, C.M. (2005). The effect of expiration dates and perceived risk on purchasing behavior in grocery store perishable categories. Journal of marketing, 69(2), 114-129.

Varley, R. (2006). Retail Product Management: Buying and Merchandising. London: Routledge.

Zhou, L., \& Li, J. (2014). Dynamic Pricing Research on Perishable Products under Consumer Strategy Behavior: Science Journal of Applied Mathematics and Statistics, 2(4), 78-84.

Publisher's Note: SSBFNET stays neutral with regard to jurisdictional claims in published maps and institutional affiliations.

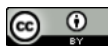

(C) 2022 by the authors. Licensee SSBFNET, Istanbul, Turkey. This article is an open access article distributed under the terms and conditions of the Creative Commons Attribution (CC BY) license (http://creativecommons.org/licenses/by/4.0/).

International Journal of Research in Business and Social Science (2147-4478) by SSBFNET is licensed under a Creative Commons Attribution 4.0 International License. 